\title{
Fuentes sobre la documentación municipal y el archivo de la villa de Madrid. Libros de acuerdos, difusión de la información y conservación documental
}

\author{
Sources on Municipal Documentation and the Archive of the Town of \\ Madrid. \\ Books of Acts, Information Diffusion and Documentary Conservation
}

\author{
Leonor ZOZAYA MONTES \\ Universidad Complutense. Madrid \\ zozaya@ghis.ucm.es \\ http://www.leonorzozaya.wordpress.com
}

\section{RESUMEN}

Se analizan los libros de inventarios, los libros de conocimientos y los libros de acuerdos del Archivo de la Villa de Madrid a finales de la Edad Media. Aquí se han utilizado para estudiar aspectos archivísticos coevos, es decir, referidos a la propia documentación municipal (tanto la archivada como la no archivada), y a los archivos capitulares. Este análisis se centra en los libros de acuerdos, que han permitido estudiar el uso cotidiano de las escrituras municipales en su contexto administrativo, averiguando dónde se hallaban, quién las guardaba o cómo se recuperaba el material disperso. De la observación de estas fuentes se desprende que aportan mucha más información sobre la documentación municipal en uso, que sobre la archivada o el propio archivo. Tal desigualdad se saca aquí a la palestra, para plantear el porqué de esa diferencia.

Palabras clave: Libros de acuerdos. Archivos municipales. Fuentes. Documentación no archivada. Madrid. Baja Edad Media.

\begin{abstract}
This article analyzes Books of Inventories, Registers and Acts from the late Middle Ages pertaining to the Town Archive of Madrid. Here they are used to study coeval aspects referring to the municipal documentation itself (it being archived or not) and to the chapter's archives. The Books of Acts are the main object of this analysis, allowing the study of the daily use of the Council's scripts in their living context and administrative reality, i.e.: who kept these documents, and when and how disperse materiel was recuperated. Observation of these sources renders more information regarding municipal documentation in use than archived documentation or the archive itself. This disparity is brought to light in order to suggest reasons for this difference.
\end{abstract}

Key words: Book of Acts. Township archives. Sources. Non-archived documentation. Madrid. Low Middle Ages.

Sumario: 1. Introducción. 2. La información sobre archivos y documentos en las fuentes. 3. La documentación no archivada: usos y contextos documentales. 3. 1. Documentación que se hallaba en el ayuntamiento. 3.2. Documentación en manos de los oficiales del concejo. 3.3. La documentación dispersa y los sistemas para recuperarla. 4. Información sobre archivos y documentación archivada. 5. Sobre el desequilibro de información: tras el rastro del uso de las escrituras. 6. Conclusiones. 


\section{INTRODUCCIÓN}

El tema de la documentación del concejo de Madrid a finales de la Edad Media (14641520) es complejo. Para reflexionar sobre las fuentes primarias que tratan sobre ello, es necesario acercarse a diversos volúmenes. Son importantes el libro de conocimientos y el libro de inventarios del archivo. Pero los principales en este estudio han sido los libros de acuerdos del concejo, que han permitido estudiar aquí qué uso se daba coetáneamente a la documentación municipal no archivada, es decir, la que circulaba por el consistorio, la que se hallaba en las manos de los oficiales del concejo así como la dispersa por la villa. También, los libros de acuerdos han servido para estudiar someramente los archivos municipales y la documentación archivada. Sobre estos dos temas ofrecen menos información que sobre la documentación no archivada.

Para intentar entender porqué las fuentes ofrecen esa diferencia de información, este artículo también estudia qué acostumbraba a hacer el cabildo con la documentación. El abanico de posibilidades era enorme: desde leerla en voz alta para divulgar sus contenidos (con medios como el pregón) hasta, en menor medida, archivarla. Antes de comenzar a profundizar en todo ello, cabe recordar que los procedimientos de comunicación medievales aunaban mecanismos orales y escritos, donde prevalecía la oralidad sobre la escritura, pues se trataba de una sociedad predominantemente analfabeta ${ }^{1}$.

\section{LA INFORMACIÓN SOBRE ARCHIVOS Y DOCUMENTOS EN LAS FUENTES}

Las principales fuentes primarias que informan sobre los propios archivos municipales y su documentación son dos libros de control archivístico: el libro de inventarios y el libro de conocimientos. Por su parte, los libros de actas, además de ofrecer datos sobre el archivo en sí y sus fondos, brindan una sustanciosa riqueza descriptiva sobre la documentación del concejo madrileño: dónde estaba, quién la manejaba o cómo se intentaba recuperar el material disperso. Procede detenerse con más detalle en la información que aporta cada volumen.

El libro de conocimientos registraba las consultas de la documentación municipal archivada. En él anotaba el escribano la que se sacaba del archivo o la que se introducía en él, así que servía para controlar el movimiento de los fondos. También informaba, en ocasiones, de quién acudía a aquellas aperturas oficiales. Se denominaba libro de conocimientos porque en origen se expedían recibos encabezados por el verbo "conocer" más el nombre de quien había presenciado la toma o la devolución documental. Con esa fórmula, la persona en cuestión se hacía responsable del movimiento de escrituras. Esos conocimientos, cosidos y encuadernados, conformaban ese volumen. Para hacerse a la idea del tipo de información que brinda, si se ingresase en el archivo un documento sobre El Real de Manzanares (pues sobre ese tema se archivaba numerosa documentación), se consignaría su ingreso y quién lo recibió.

1 Miguel Ángel LADERO QUESADA: "Aspectos de la comunicación en los siglos XIV y XV" Boletín de la ANABAD, XXX (1980), 2, p. 186; todo en pp. 185-207. 
Ese fue el caso dado en el año 1505, cuando Gregorio Arloaga recibió varios procesos que le entregó el Bachiller Orduña tocantes a los pleitos que Madrid seguiría con el Duque del Infantado sobre el amojonamiento de El Real Manzares ${ }^{23}$.

Por otro lado, el libro de inventarios del Archivo de la Villa de Madrid brinda numerosos datos sobre los fondos rchivados. Se compone de descripciones documentales. Cuenta con interesantes listas, regestos y resúmenes -según el caso- de la documentación del archivo, se usase o no de forma coeva en la política municipal. El volumen servía al ayuntamiento para controlar la documentación municipal archivada y para facilitar su uso en las gestiones políticas ${ }^{4}$. Por ejemplo, si se inventariase un documento sobre el mismo tema antes mencionado, se describiría el material del soporte, su función, si tenía sellos, etcétera. Por ejemplo, "Un treslado de dos cartas del rrey don Alonso fecho en pergamino a la larga contra El Rreal de Mançanares", catalogado con el número LII en el inventario iniciado en septiembre de 1481 por el corregidor Rodrigo de Mercado, el regidor Diego de Madrid, el doctor Alonso Fernández de Madrid y el bachiller Diego Díaz, letrados de la villa ${ }^{5}$.

Aunque a primera vista estas fuentes primarias acaso puedan deslumbrar a los estudiosos de los archivos - pues ofrecen información sobre sus fondos-, adolecen de varios problemas para historiar. Entre ellos, omiten datos sobre el estado físico del archivo (como su evolución material) y no siguen una cronología sistemática ${ }^{6}$. Pero el principal problema radica en que se circunscriben únicamente a la documentación archivada, como si estuviera limitada a un compartimiento estanco. Se refieren a ella como si siempre permaneciese aislada entre otros documentos, cuando la realidad administrativa de la villa era muy rica y se desenvolvía en unos contextos complejos.

Además, ambos libros sólo informan de la presencia de los fondos documentales en el archivo, que representaban realmente un pequeño tanto por ciento de las escrituras municipales, frente a la cuantiosa cantidad de ellas que transitaba por la villa madrileña cotidianamente.

\footnotetext{
2 AVM, Libros Manuscritos, 68 , fols. $1 r^{\circ}$ a $2 v^{\circ}$.

${ }^{3}$ Así, el escribano Gregorio de Zuloaga afirmaba en 1505: "conosco que rreçebí de vos, el bachiller de Orduña, el dicho proçeso en que ay las pieças siguientes [...] E porque es verdad que las rreçebí por mandado de los señores oydores, e yo daré cuenta dél cada e quando que me fuere demandada, os di este conosçimiento firmado de mi nonbre, fecho en el lugar de Tudela de Duero, a onze días del mes de agosto de mill e quinientos e çinco años, Gregorio de Çuloaga", AVM, Libros Manuscritos, 68, fols. $1 r^{\circ}-2 r^{\circ}$.

4 Sus descripciones documentales, lejos de ser objetivas, eran tendenciosas, y revelan para qué utilizaba el gobierno municipal sus escrituras. Las usaba principalmente con el fin de regular las normas de gobierno, para preservar el honor de los privilegiados y para defender los derechos de la villa y los villanos. De todas esas funciones, estudié la salvaguarda de los derechos y los privilegios del concejo madrileño contra las intromisiones monárquicas en Leonor Zozaya Montes: "Archivos municipales al servicio de su propietario. El caso de los archivos del concejo madrileño ante las enajenaciones regias", Actas de la Reunión Científica de la Fundación Española de Historia Moderna. Homenaje a D. Antonio Dominguez Ortiz en el centenario de su nacimiento, en prensa.

${ }^{5}$ AVM, Libros Manuscritos, 19, fol. $3 r^{\circ}$.

${ }^{6}$ Ninguno de los dos libros estuvieron concebidos originalmente como volúmenes unitarios. Son volúmenes misceláneos de reunión de documentos. Y, como es habitual, muchas páginas se perdieron antes de ser encuadernadas. El libro de conocimientos, además, apenas cuenta con información de las fechas aquí estudiadas.
} 
Los libros de acuerdos, fuente fundamental en esta investigación ${ }^{7}$, podían contener información en esa misma línea (sobre las consultas archivísticas o sobre el mandato de hacer inventarios). Pero además cuentan con información de la que los anteriores volúmenes carecen, que permiten conocer en qué contextos administrativos se manejaba la documentación municipal en Madrid y cómo era el archivo del ayuntamiento. En esos libros, el escribano del cabildo levantaba el acta de las deliberaciones acordadas por el gobierno municipal en sus celebraciones capitulares; de ahí su nombre. Eran fundamentales para gestionar la política de la villa ${ }^{8}$.

Los libros de acuerdos ofrecen cuantiosa información sobre la documentación municipal en general, incluida la que no estaba en el archivo. También tratan sobre los contextos administrativos donde circulaban las escrituras, sobre los oficiales que las usaban y custodiaban, o sobre los sistemas utilizados por el concejo para recuperarlas. Sitúa a la documentación en un contexto "vivo", muestra la relación de ese material escrito con la oralidad, con la gestualidad, con las personas que lo manejaban, dónde y en qué circunstancias. Informa de dónde se hallaba de forma cotidiana, quién la usaba, dónde, cómo, si se copiaba, reverenciaba o publicaba. Permiten así acercarse al uso social de la documentación, abriendo así un abanico enorme de posibilidades de análisis.

\section{LA DOCUMENTACIÓN NO ARCHIVADA: USOS Y CONTEXTOS DOCUMENTALES}

Los libros de actas informan sobre infinidad de documentos que se hallaban en las dependencias del ayuntamiento, que se escrituraban allí mismo o que se introducían en el consistorio temporal o definitivamente. Otra parte importante de documentos se encontraba en poder de los oficiales del concejo, quienes los transportaban a lo largo y ancho de la villa. En numerosas situaciones, el material escrito acababa traspape-

7 Se han usado las transcripciones publicadas en los siguientes volúmenes: Libros de acuerdos del concejo madrileño, 1464-1485, t. I (transcripción de Agustín MILLARES CARLO y Jenaro ARTILES), Madrid, Artes Gráficas Municipales, 1932. Libros de acuerdos del concejo madrileño, 1486-1492 (transcripción de Agustín GÓMEZ IGLESIAS) t. II, Madrid, Artes Gráficas Municipales, 1970. Libros de acuerdos del concejo madrileño, 1493-1497, t. III (transcripción de Carmen RUBIO PARDOS; Trinidad MORENO VALCÁRCEL; Concepción DE LA FUENTE COBOS y Emilio MENESES GARCÍA), Madrid, Raycar, 1979. Libros de acuerdos del concejo madrileño, 1498-1501, t. IV (transcripción de Carmen RUBIO PARDOS, Rosario SÁNCHEZ GONZÁLEZ y María del Carmen CAYETANO MARTÍN), Madrid, Raycar, 1982. Libros de acuerdos del concejo madrileño, 1502-1515, t. V (transcripción de Rosario SÁNCHEZ GONZÁLEZ y María del Carmen CAYETANO MARTÍN), Madrid, Artes Gráficas Municipales, 1987.

8 Además, ofrecerían datos sobre otros documentos relacionados con aquel asunto considerados de forma coeva de menor importancia, que por ello no se archivaban (como cuando se otorgaban y enviaban cartas mensajeras. Se otorgaron dos cartas mensajeras, "una para el duque del infantado y otra para El Rreal de Manzanares", con la intención de que los caballeros del monte guardaran la posesión de los montes de la villa, en 22 de septiembre de 1480, Libros de acuerdos del concejo..., t. I, p. 43. También se otorgó otra, y fueron varios oficiales del concejo, en 10 de diciembre de 1481, Libros de acuerdos del concejo..., t. I, p. 146. 
lado. Para que la gente lo devolviera, el ayuntamiento ingenió varios mecanismos de solicitud documental. Véase qué sucedía con esas escrituras.

\section{1. DOCUMENTACIÓN QUE SE HALLABA EN EL AYUNTAMIENTO}

Un acercamiento a los libros de acuerdos, aunque sea superficial, confirma que numerosos documentos circulaban cotidianamente por la sala del ayuntamiento, acompasando las gestiones burocráticas rutinarias de los oficiales que trabajaban para la institución.

Ese material escrito procedía de diferentes lugares. Parte llegaba cotidianamente de fuera de la institución. Era normal que entrase documentación en el consistorio y que posteriormente se sacara, se copiase o permaneciera en él, dependiendo de su utilidad o su función. Y aunque quedara en la sala del consistorio, pocas veces se archivaba9.

Otra parte del material escrito se originaba en cada sesión capitular, ya que en el concejo se solían expedir escrituras prácticamente por cualquier comisión municipal. Valga por caso lo sucedido el 22 de agosto de 1492, cuando el concejo mandó escribir al empedrador, para que fuese a la villa a empedrar, y también ordenó otorgar una carta para que Gonzalo Gómez de Vitoria diera un memorial a la villa de Madrid ${ }^{10}$.

Era relativamente normal que, cuando una carta se presentaba en el concejo, la institución la copiase (haciendo un traslado, que era una copia autenticada) y se quedase con la copia pero no con el original. Así sucedió por ejemplo en diciembre de 1487. Llegó al consistorio Juan Romo, vecino de Madrid, y presentó una carta de los Reyes Católicos, de la que el ayuntamiento pidió un traslado ${ }^{11}$. Éste se quedaría en el cabildo (durante cierto tiempo no explicitado por la fuente), y el citado Juan Romo se llevó el original. Lo mismo hizo Juan de Laredo, en nombre del tesorero general de las Hermandades, cuando presentó una carta de repartimiento de los diputados de la Santa Hermandad. Aunque la carta se copiase en el libro del concejo ${ }^{12}$, el apoderado iba a llevarse el original.

En una línea de actuación similar, el ayuntamiento enviaba documentación original (en vez de copias). Así sucedió en septiembre de 1501. El cabildo convino enviar a Ciudad Real varios documentos por motivos relacionados con el pleito que mantenía con El Real de Manzanares. Mandó un privilegio regio, de cuando "el rey don Alonso dividió los términos" y otro del año 1404. También envió una provisión del licenciado Montalvo de 1454. Se llevó todo ello Ruy Díaz, quien lo envió, y lo recibió su padre, Manuel Rodríguez, para entregárselo al comendador ${ }^{13}$.

9 Hay un cuadro esquemático que condensa los escasos acuerdos respecto a cuando se archivaba documentación. Además, como se verá posteriormente, era documentación "selecta", sobre todo sentencias y privilegios (como cuando se ordenó que se metieran los privilegios en el arca (19 de enero de 1502, Libros de acuerdos del concejo..., t. V, p. 7).

${ }^{10}$ Libros de acuerdos del concejo..., t.II, p. 356.

117 de diciembre de 1487, Libros de acuerdos del concejo..., t. II, p. 95.

1223 de agosto de 1488, Libros de acuerdos del concejo..., t. II, p. 126 y 127.

1327 de septiembre de 1501, Libros de acuerdos del concejo..., t. IV, p. 320. 
La documentación transitaba por diversos lugares rápidamente. Un manuscrito podía ser transportado cambiando de sitio en un breve lapso temporal ${ }^{14}$. Vaga un botón de muestra. El 13 de marzo de 1500, el escribano guardaba la famosa Sentencia de Montalvo, pero ese día tuvo que mostrársela al corregidor para que examinara parte del texto ${ }^{15}$. Lo sucedido después que la leyó es una incógnita, sobre la que cabría plantear varias dudas, por ejemplo ¿se la devolvió o se la quedó en su posada (donde acostumbraba a llevar documentos)? Suponiendo que el último caso fuese afirmativo, ¿durante cuánto tiempo la guardó? Un seguimiento del rastro de las manos por las que pasó después, delataría la múltiple trayectoria de ese documento. Pero sus huellas son difíciles de seguir, debido en parte a la imprecisión con que las fuentes acostumbran a referirse a él ${ }^{16}$. En cualquier caso, dado que el cabildo consideraba importante dicha sentencia, la guardaba en el archivo normalmente, aunque siguiese sacándola con frecuencia para consultarla ${ }^{17}$.

\subsection{DOCUMENTACIÓN EN MANOS DE LOS OFICIALES DEL CONCEJO}

El trajín de la documentación municipal también era considerable fuera de las puertas del cabildo. Numerosos oficiales portaban escrituras públicas dentro y fuera del ayuntamiento, atendiendo a las gestiones municipales; incluso las custodiaban ellos mismos. Eso hacían letrados, bachilleres, regidores, corregidores, escribanos, procuradores generales y otros.

En efecto, letrados y bachilleres consultaban documentación municipal constantemente, para defender a la villa mediante pleitos y litigios ${ }^{18}$. El corregidor también examinaba las escrituras, tanto que no extrañaba que hiciera llevar el arca de docu-

14 Por ello, es prudente evitar generalizar con un dato con respecto a la preservación de algunos documentos, porque aunque en ocasiones se mencionase dónde se guardaban, podían cambiar de lugar con frecuencia.

${ }_{15}$ Con el fin de ver y cumplir la normativa relativa a las formalidades que debían darse en las celebraciones de ayuntamiento. Libros de acuerdos del concejo..., t. IV, p. 183.

16 Es un problema generalizado para un historiador que se acerque a esas fuentes. No obstante, sería interesante poder hacer un seguimiento de varios documentos importantes durante unos años, para estudiar estadísticamente cuánto tiempo permanecían dentro del archivo municipal y cuánto fuera de él.

${ }^{17}$ Así se registra en el inventario citado de 1481: "Sentençias del dotor de Montalvo y otros jueses y el memorial de las [en blanco], LIIII", AVM, Libros Manuscritos, 19, fol. $3 \mathrm{r}^{\circ}$. Ha de tenerse en cuenta que posiblemente para hacer los inventarios guardaban previamente la documentación importante. No creo que sea casualidad que en 1514 se mandó guardar la documentación (3 de julio de 1514, LAVM, V, p. 287), y el mismo año empezasen un inventario el corregidor Pedro de Vaca y los regidores Francisco de Vargas y Francisco de Herrera. AVM, Libros Manuscritos, 19, se inicia en el fol. 10r ${ }^{\circ}$.

${ }_{18}$ Por ejemplo, un bachiller, además letrado, debería ver un privilegio y luego debería hacer relación en el ayuntamiento con su parecer, el 14 de julio de 1490, Libros de acuerdos del concejo... t. II, p. 222. 
mentos del concejo a su casa ${ }^{19}$. Incluso, los porteros del concejo también guardaban papeles del ayuntamiento ${ }^{20}$.

Los regidores igualmente acarreaban una "envoltura" con cartas y escritos ${ }^{21}$, que llevaban al ayuntamiento cartas reales de confirmación de ordenanzas ${ }^{22}$. Asimismo, bajo su poder solía quedar documentación original ${ }^{23}$.

Asimismo, el comendador manejaba documentos para usarlos en las gestiones municipales ${ }^{24}$. También guardaba en su casa escrituras cruciales, como las relativas a los pleitos de El Real de Manzanares ${ }^{25}$.

De todos los oficiales de la villa, posiblemente era el escribano del concejo quien manejaba y custodiaba mayor cantidad de documentación pública ${ }^{26}$. También era normal que se le encomendase guardar documentación fiscal, de rentas o de cuentas. Por ejemplo, el 7 de agosto de 1514 se mandó que se pusieran en su poder los pliegos de la información de los maravedís que sumaban las rentas y las cuentas de la villa ${ }^{27}$.

En unas ocasiones, casi como sencillo correo, el escribano debía entregar a otros oficiales documentos administrativos, fundamentales para la gestión económica y la política municipal ${ }^{28}$; como cuando se ordenó que en el mismo día el escribano del concejo Antón Dávila diera las cédulas del repartimiento a los sexmeros de la vi1la. En otras ocasiones similares, debía custodiar y luego entregar originales, entre ellos, sentencias y cartas reales. Así sucedió el 28 de enero de 1502, cuando entregó al comendador Amoroso una carta ejecutoria original de El Real de Manzanares y

${ }^{19}$ Eso era comprensible, dado que en su posada se celebraban algunos ayuntamientos. El arca estaba en su casa el 21 de agosto de 1504, Libros de acuerdos del concejo..., t. V, p. 171. Se ayuntaron allí, por ejemplo, el 21 de mayo de 1488, Libros de acuerdos del concejo..., t. II, p. 119, o el 7 de mayo de 1512, Libros de acuerdos del concejo..., t. III, p. 175.

${ }^{20}$ Valga por ejemplo el del 9 de enero de 1503, cuando se acordó librar la martiniega a algunos conventos de la villa, dejando los traslados de los privilegios al escriba.

${ }^{21}$ El material versaba sobre una apelación, 27 de julio de 1500, Libros de acuerdos del concejo..., t. IV, p. 213.

${ }^{22}$ En concreto, tres cartas reales de confirmación de las ordenanzas del vino para que las entregara en el ayuntamiento llevó el 5 de enero de 1494, Libros de acuerdos del concejo..., t. III, p. 114.

${ }_{23}$ Por ejemplo, en poder del regidor Francisco de Luzón quedó un mandamiento en 9 de octubre de 1482

${ }^{24}$ No era raro que el concejo ordenara darle una ejecutoria original para que la usara según procediera en las gestiones municipales, como el 28 de enero de 1502. El mismo día, el escribano del concejo le entregó otra ejecutoria original sobre El Real, para llevarla a Ciudad Real, Libros de acuerdos del concejo..., t. V, p. 9.

25 El 15 de mayo de 1503 estaban en casa del comendador Amoroso (Juan Amoroso). Libros de acuerdos del concejo..., t. V, p. 103.

${ }^{26}$ Desde el último tercio del siglo XV, una familia de escribanos empezó a controlar las escribanías: Alonso González y sus hijos Pero González y Juan González de Madrid. En 1484, renunció al título de escribano del concejo a favor de su sobrino Antón de Ávila. Éste también renunció el título en favor de su hijo Gaspar de Ávila en 1519. Pilar RÁBADE OBRADÓ: Orígenes del notariado madrileño: los escribanos públicos en el siglo XV, Madrid, Colegios Notariales de España, 2001, pp. 157-170. Para una época posterior, sobre esos oficiales véase Leonor ZOZAYA MONTES: De papeles, escribanias y archivos: escribanos del concejo madrileño (1557-1610), Madrid, CSIC, 2011.

${ }^{27}$ Libros de acuerdos del concejo..., t. V, 293.

${ }_{28} 29$ de noviembre de 1512, Libros de acuerdos del concejo..., t. V, p. 206. 
a Alonso de Bobadilla las sentencias de El Real, que sumaban 238 folios de pliego entero $^{29}$.

El escribano también custodiaba de forma particular documentos escriturados por él y por sus sucesores. Si se daba el caso de que el cabildo necesitaba estudiarlos, podía pedirle que se los mostrara ${ }^{30}$, o que se los llevase a la sede capitular, mezclándose en cierto sentido los ámbitos público y privado. Un caso significativo acaeció en 1481, cuando el escribano del concejo Juan González tuvo que buscar todas las escrituras sobre la plaza del ayuntamiento que habían pasado ante su padre, Alonso González. Debía entregárselas al pesquisidor Juan Ramírez y al corregidor Rodrigo de Mercado, con el fin de verlas y hacer que se cumplieran, administrando así justicia en la villa ${ }^{31}$. También aconteció algo parecido en 1513; el escribano del concejo se vio obligado a entregar al corregidor todos los procesos pendientes que hubieran pasado ante él (para lograr concluirlos), bajo pena de una multa de dos mil maravedís ${ }^{32}$.

Según va observándose, cuantiosos oficiales manejaban y guardaban documentación municipal, apoyados por la confianza que el ayuntamiento depositaba en ellos. Ese sistema dependía de su seriedad y honradez. Por tanto, conociendo la condición humana, estaba abocado a que el material se dispersara y terminase en manos de personas irresponsables, desconocidas o indeseadas para el ayuntamiento. La pérdida de documentos municipales provocaba múltiples inconvenientes irreparables para la institución, porque muchos de ellos tenían valor administrativo, y la villa necesitaba controlarlos y usarlos en las gestiones de la política municipal con diversos fines ${ }^{33}$.

\subsection{LA DOCUMENTACIÓN DISPERSA Y LOS SISTEMAS PARA RECUPERARLA}

Ante las situaciones de descontrol documental, las autoridades consistoriales ingeniaron varios sistemas para recuperar las escrituras públicas (las que el concejo entendía que de un modo u otro le pertenecían). Esos métodos evolucionaron con el paso del tiempo, según la experiencia iba avezando al concejo. En inicio se basaban en las clásicas cláusulas penales pecuniarias y espirituales de los diplomas. Sin embargo, entrado el siglo XV se fueron endureciendo hasta el punto de poder excomulgar a quien poseyera documentación de la villa ilícitamente.

29 Libros de acuerdos del concejo..., t. V, p. 10.

30 El 20 de junio de 1513 tuvo que mostrar todas las provisiones que tuviera a un vecino de Manzanares sobre un pleito "que traen con Campillo e Monesterio", Libros de acuerdos del concejo..., t. V, p. 235.

31 Acaeció el 13 de agosto de 1481, Libros de acuerdos del concejo..., t. I, p. 121.

32 Lo mismo encargaron al procurador general quien, para gestionar los pleitos, también tuvo que conservar la documentación en curso. Todo sucedió el 13 de junio de 1513, Libros de acuerdos del concejo..., t. V, p. 232.

33 Para épocas posteriores, cabe destacar el valor económico de la documentación administrativa, que era lo que en parte la revalorizaba. Al respecto, vid. Leonor Zozaya Montes: "Mermas de poder económico debido a la pérdida documental en los archivos de la Villa de Madrid en Tiempos de Felipe II", en: Francisco J. ARANDA PÉREZ (coord.): El mundo rural en la España Moderna, Cuenca, Eds de la Univ. de Castilla - La Mancha, 2004, pp. 1295-1306. 
Para resumir esa evolución, hay que remontarse a la Sentencia de Alfonso Díaz de Montalvo, fechada en 1454, impresa en 1484 y revalidada durante sucesivas centurias. Regulaba las normas de la elección de oficios municipales, tema que motivaba continuas luchas entre regidores e hidalgos ${ }^{34}$. La sentencia citaba que las pesquisas del jurisconsulto en Madrid habían probado que algunas personas habían tomado del arca del concejo de la villa privilegios, ordenanzas, fueros y otras escrituras. Montalvo había conseguido la licencia del rey para pedir que las devolvieran al arca en diez días, bajo pena de confiscación de todos sus bienes para la cámara real ${ }^{35}$.

Otro hito importante sucedió años después, a inicios de diciembre de 1491. El pesquisidor de la villa intentó que los regidores, procuradores, escribano concejil y otras personas, como los sesmeros, averiguasen quién tenía documentación a favor de la villa para que la devolvieran. A finales del mismo mes, el pesquisidor volvió a convocarles, con la intención de que declarasen quién tenía algún documento de las características anteriores, para que lo devolviera en tres días y quedase guardado en el arca del concejo. Su finalidad explícita era cobrar deudas, para que redundasen en provecho de la villa. Además, pretendía tejer una red social de devoluciones, pues pidió también que declarasen -jurando ante el escribano- si conocían a cualquier persona que tuviera algún papel, para que lo devolviera. El pesquisidor expresó el deseo de que si lo hacían así les ayudase Dios, pero si no lo hacían les deseaba mal, como a quienes perjuraban a sabiendas ${ }^{36}$.

Diecisiete años más tarde, en 1508, el concejo endureció el método para recuperar documentación dispersa, cuando comenzó a usar un sistema basado en amenazas de excomunión, con motivo del pleito que Madrid litigaba con El Real de Manzanares. Un escribano, quien guardaba una parte de las escrituras de ese litigio, anunció que otra parte se había quedado en Valladolid y otra se había perdido; todo ello, pese a sus profusas pero infructuosas diligencias para recuperar el material escrito. Al menos, había conseguido redactar un memorial sobre la documentación que faltaba; memorial que solicitó estudiar el procurador de la villa, Miguel de Sazedo. Tras verlo, pidió que el vicario de Madrid ordenase leer cartas de excomunión en El Real

${ }^{34}$ La sentencia de Alfonso Díaz de Montalvo, de 1454, regulaba las normas de la elección de oficios municipales. Sobre la confirmación de esa ordenanza en los siglos XV y XVI, vid: Juan Manuel CARRETERO ZAMORA: Cortes, monarquía, ciudades. Las cortes de Castilla a comienzos de la Época Moderna (1476-1515), Madrid, Siglo XXI, 1988, pp. 322-330. Existen numerosas reediciones facsimilares, como: Alfonso DÍAZ DE MONTALVO: Compilación de Leyes del Reino. Ordenamiento de Montalvo, (reed. de 1584, ed. Facsímil, Valladolid, Lex Nova, 1986).

35 "Otrosí por quantto por la dicha pesquisa se prueba que algunas personas sacaron y llevaron de la arca del conçejo de la dicha villa los previlexios y hordenanças y fueros y otras scripturas, por ende mando de parte del dicho rrey a todas las dichas personas que ansí [tachado: mismo] tomaron y sacaron y llevaron las dichas scripturas que fasta diez días primeros siguientes las tornen a la dicha arca del dicho conçejo so pena de perdimiento y confiscaçión de todos sus vienes para la cámara y fisco del dicho señor rrey. [Al margen:] que se buelban los previlexios y fueros y hordenanças". Transcrito en el volumen: Libro segundo, en el que se encontrará toda luz de los privilegios que la coronada villa de Madrid tiene en poder governarse por sí sola con sus cavalleros, rregidores, concordias, estatutos y hordenanzas que tiene para la forma de su gobierno [...] que lo rebalidó desde los años 1454 hasta el presente de 1720, AVM, Libros Manuscritos, 112, p. 23.

${ }^{36}$ Libros de acuerdos del concejo..., 9 de diciembre de 1491 y Libros de acuerdos del concejo..., 30 de diciembre de 1491 . 
de Manzanares para reclamar la documentación que le faltaba a Madrid sobre ese proceso $^{37}$.

El ayuntamiento había usado anteriormente sentencias de descomunión para castigar a quien usurpase tierras a la villa u ocupase cualesquier términos y bienes muebles $^{38}$. Pero nunca antes las había utilizado para reclamar documentos municipales. Desde de entonces, el concejo madrileño generalizó el método de pedir escrituras públicas mediante amenazas de excomunión ${ }^{39}$. Así, se sacaron cartas para descomulgar en el año 1520. De ello informa el mandato de un teniente de corregidor en Madrid, que daba noticia de que el mismo Miguel de Sazedo guardaba bajo su poder unos documentos sobre aquel pleito de El Real de Manzanares, más unas cartas de descomunión que se habían sacado "sobre çiertas escripturas". Debía entregárselo todo al escribano Antón Dávila -quien iba a Valladolid a litigar-, bajo pena de diez mil maravedís ${ }^{40}$.

Los pasos descritos, andados a favor de la recuperación de la documentación municipal, parecen estar informando de una temprana conciencia del concepto de escrituras públicas, que pretendía evitar que estuvieran en manos privadas, entre las que también incluía al cabildo y a los oficiales que trabajaban para la villa ${ }^{41}$.

\section{INFORMACIÓN SOBRE ARCHIVOS Y DOCUMENTACIÓN ARCHIVADA}

Los libros de acuerdos, además de ofrecer infinita información sobre la documentación municipal, sus usos y sus contextos, también ofrecen datos sobre los archivos de la época ${ }^{42}$. Resumiendo brevemente su trayectoria, el ayuntamiento madrileño con-

37 Sucedió el 2 de septiembre de 1508. AVM, Secretaría, 1-480-2.

38 Así lo hizo el 12 de mayo de 1484, Libros de acuerdos del concejo..., t. I, pp. 326 y 327.

39 Incluso años más adelante, desde 1574, se comenzó a poner en práctica la publicación de paulinas, que eran igualmente cartas de excomunión, pero con el agravante de sospechaba que el material había sido robado u ocultado maliciosamente. Analizo a fondo lo sucedido desde mediados del siglo XVI hasta inicios del siglo XVII en: Leonor ZOZAYA: "The Recuperation and Conservation of Municipal Documents in Early Modern Age Madrid", Journal of History, Literature, Science and Tecnology (JHLiST) 1, 2011, en prensa.

${ }^{40}$ Se citó "las cartas de descomunión que sobre çiertas escripturas se sacaron". El dinero iría parar a la Cámara Real, y el teniente era Alonso Bernaldo de Gros. El mandato estaba fechado el 11 de abril de 1520. AVM, Libros Manuscritos, 68 , fol. $2 \mathrm{v}^{\circ}$.

${ }^{41}$ Desde luego, la distinción quedó perfectamente perfilada años después, aproximadamente desde mediados del siglo XVI, Leonor ZOZAYA: "The Recuperation and Conservation...".

${ }^{42}$ Estudiaron la evolución de esos archivos en la época, aunque durante mucho tiempo pensaban que era sólo uno que se denominaba indistintamente arca de escrituras o de privilegios: Timoteo DOMINGO PALACIO: Manual del empleado en el Archivo General de Madrid, con una reseña histórica del municipio. Madrid, Imp. y Lit. de los Asilos de San Bernardino, 1875, 18-21. Agustín GÓMEZ IGLESIAS: "Origen, evolución e incidencias acerca del Archivo de la Villa de Madrid", Anales del Instituto de Estudios Madrileños, X (1974), p. 30; María del Carmen CAYETANO MARTÍN: "Fuentes para la Historia del Madrid Medieval en el Archivo de Villa", en Juan Carlos de MIGUEL RODRÍGUEZ (ed.): El Madrid Medieval. Sus Tierras y sus Hombres, 6, Madrid, Asoc. Cultural Al-Mudayna, 1990, pp. 23-26, y de la misma autora: Archivo de Villa (Guia del Archivo), Madrid, Ayuntamiento, 2001, pp. 12 y 13. Miguel Ángel LADERO QUESADA: "Three Examples of Spanish Metropolitan Archives: Barcelona, Seville, Madrid”, en M. V. ROBERTS (ed.): Archives and the Metropolis, Londres, Guidhall 
taba con dos archivos que tenían forma de arcas, que guardaba inicialmente en el consistorio. En el año 1481, las fuentes comenzaron a mencionar el arca de escrituras (o del concejo). Años después, en 1495, también empezaron a dar cuenta de la existencia de lo que parecía ser otro $\operatorname{archivo}^{43}$, el arca de privilegios, que comenzó a ser custodiado desde 1512 en el Monasterio de Santo Domingo el Real extramuros de la villa $^{44}$. Dada esa doble existencia, puede hablarse de los archivos en plural, o de los archivos en singular, cuando se trate del nombre genérico.

Los acuerdos del concejo informan sobre multitud de aspectos del archivo y sobre una parte de la documentación que había en él, contando quién, cómo y para qué se usaba. También narran las normas teóricas que regían el funcionamiento del archivo sobre el sistema de guarda bajo tres llaves, que se confrontaban con las irregularidades prácticas que se daban cotidianamente ${ }^{45}$. Téngase en cuenta que en junio de 1500 se publicó en Sevilla la famosa real provisión que regulaba el funcionamiento de los archivos de los ayuntamientos del reino, aunque ya antes se conocía esa normativa en la villa madrileña ${ }^{46}$.

Sin embargo, los datos que ofrecen los libros de actas sobre los archivos y sus fondos son escasos, en términos cuantitativos, comparados con los numerosos datos que brindan sobre la documentación en curso y dispersa por la villa. Es chocante contabilizar los escasos acuerdos que dedicaban los capitulares al tema del archivo y a sus fondos. De hecho, son tan pocos que he podido condensarlos en el cuadro 1, titulado Mención en los libros de acuerdos a los archivos (1461-1515).

El citado cuadro permite realizar varias observaciones. Una, que la serie de las actas comienza en el año 1461, pero hasta veinte años después no aparece una mención al archivo, en 1481. Otra, que desde 1481 hasta 1515 -tras más de treinta años-, hay sólo veintiún acuerdos que versan sobre los archivos madrileños y sus fondos (más una norma municipal del año 1499 sobre su regulación) $)^{47}$. Otra observación: que la poca documentación que se archivaba consistía mayoritariamente en sentencias y

Library Publications - Centre for Metropolitan History, 1998, p. 39-41. Leonor ZOZAYA MONTES: "Historiografía, fuentes e Historia del Archivo de la Villa de Madrid en el Tránsito de la Edad Media a la Edad Moderna", en IGNACIO SÁNCHEZ AYUSO (ed): "Una reflexión historiográfica sobre la Historia de Madrid en la Edad Media", Madrid, Almudayna, 2011, pp. 141-165.

${ }_{43}$ Para deducir que eran dos archivos diferentes ha sido fundamental el estudio dedicado a una época posterior, los años 1561 a 1572, sobre ambos archivos y sus denominaciones. Leonor ZOZAYA MONTES: "El monasterio de Santo Domingo el Real de Madrid como custodio de un arca del archivo de la Villa durante la época de Felipe II", Iglesia y Religiosidad en España. Historia y Archivos. Guadalajara, ANABAD-AAAHPG, 2002, t. III, pp. 1513-1526.

${ }^{44}$ Leonor ZOZAYA MONTES: "Historiografía, fuentes e Historia del Archivo.... Allí estuvo hasta 1572, Leonor ZOZAYA MONTES: "El monasterio de Santo Domingo el Real de Madrid como custodio de un arca...".

45 Todo ello en Leonor ZOZAYA MONTES: "Historiografía, fuentes e Historia del Archivo...". Acaso también pueda considerarse irregularidad el hecho de que el arca de privilegios del ayuntamiento se comenzase a custodiar, a inicios del siglo XVI, en el Monasterio de Santo Domingo el Real, cuando ya se había publicado la conocida pragmática que cito en la nota siguiente.

46 Respecto a dicha pragmática, sus antecedentes, sus trascendentales consecuencias y su conocimiento en Madrid, vid. Leonor ZOZAYA MONTES: "Una revisión sobre las periodizaciones archivísticas en la Edad Moderna Española", Documenta et Instrumenta, 6 (2008), pp. 133-145; todo en pp. 119-145.

${ }^{47}$ Contabilizo e incluyo incluso el acuerdo donde la palabra arca está implícita, de mayo de 1499. 
privilegios para usar en pleitos con los que la villa intentaba preservar su patrimonio, sus preeminencias y su integridad territorial ${ }^{48}$. El proceso de El Real de Manzanares se mencionaba con mayor frecuencia, que además fue el más duradero que litigó la villa ${ }^{49}$.

Cuadro 1. "Mención en los libros de acuerdos a los archivos (1461-1515)"

\begin{tabular}{|c|c|}
\hline$F E C H A$ & INFORMACIÓN DEL ACUERDO \\
\hline 10 diciembre 1481 & $\begin{array}{l}\text { Que las tres llaves que tiene Diego Díaz, bachiller y letrado de la villa, del arca del concejo, } \\
\text { las dé: una al escribano y dos a los regidores alcaldes alzadas. }\end{array}$ \\
\hline 28 febrero 1483 & $\begin{array}{l}\text { Que se caten las escrituras del arca del concejo para comprobar quiénes tienen vecindad en } \\
\text { Madrid y de qué han de gozar. }\end{array}$ \\
\hline 21 diciembre 1487 & $\begin{array}{l}\text { Que se abra el arca del concejo de escrituras, la que está en la iglesia de San Salvador; dice } \\
\text { qué oficiales han de catar las escrituras. }\end{array}$ \\
\hline 5 mayo 1488 & $\begin{array}{l}\text { Pago de } 28 \text { reales para pagar un arca que se compró, para poner en la cámara nueva del } \\
\text { concejo, en que se pongan las escrituras del concejo. }\end{array}$ \\
\hline 21 mayo 1488 & $\begin{array}{l}\text { Es menester catar el arca del concejo para sacar las escrituras tocantes al Real Manzanares. Como } \\
\text { dos llaves no se hallan, mandan descerrajar dos cerraduras, y que mientras se cierre por una. }\end{array}$ \\
\hline 3 julio 1489 & $\begin{array}{l}\text { Se mandan comprar alfombras para el concejo, una para poner encima el arca de la cámara } \\
\text { del ayuntamiento. También, que se compre una cerradura para el arca y un banco donde se } \\
\text { siente el escribano a escribir. }\end{array}$ \\
\hline 30 diciembre 1491 & $\begin{array}{l}\text { El pesquisidor quiere informarse de cuáles son las escrituras, privilegios y sentencias que la } \\
\text { villa tiene en su favor, y qué deudas se deben. Quiere recoger la documentación y ponerla } \\
\text { en el arca del concejo de la villa. }\end{array}$ \\
\hline 2 diciembre 1493 & $\begin{array}{l}\text { Que se ponga la cerradura en el arca y se traiga al arca el pendón de la villa. [Parece ser la } \\
\text { misma que el arca de escrituras.] }\end{array}$ \\
\hline 28 noviembre 1494 & Que se saque del arca la sentencia original sobre Pinto, para el plazo del Congosto, y se envíe. \\
\hline 5 enero 1495 & $\begin{array}{l}\text { Que el mayordomo haga hacer una reja delante del arca de los privilegios que está en la } \\
\text { Iglesia de San Salvador, a vista de los regidores que residen. }\end{array}$ \\
\hline 23 de mayo de 1499 & $\begin{array}{l}\text { Que se metan [supuestamente, en el arca] los privilegios que llevó el comendador y se } \\
\text { busquen los que faltan, y estén presentes Antonio de Luzón y Gonzalo de Monzón }\end{array}$ \\
\hline $\begin{array}{l}19 \text { octubre } 1499 \\
\text { [Era un mandato } \\
\text { regio para todo el } \\
\text { reino, para jurar } \\
\text { con cada nuevo } \\
\text { cargo] }\end{array}$ & $\begin{array}{l}\text { Traslado de ordenanzas sobre gobernación de los reinos, que los reyes mandan jurar a los } \\
\text { nuevos capitulares u oficiales que fueren recibidos en el concejo, que mandan hacer un arca } \\
\text { donde estén los privilegios y las escrituras del concejo, con: } \\
\text { - tres llaves (para el justicia, el escribano del concejo y un regidor) } \\
\text { - dos libros: uno de privilegios y sentencias, otro de provisiones y cédulas. } \\
\text { También manda hacer arca y libro para cárcel (de presos). }\end{array}$ \\
\hline 28 diciembre 1499 & $\begin{array}{l}\text { Que se metan los privilegios en el arca que trae el comendador, y que estén presentes el } \\
\text { alcalde y Antonio de Luzón. }\end{array}$ \\
\hline 16 marzo 1500 & $\begin{array}{l}\text { Se saque del arca de privilegios la sentencia de Pero Álvarez, para dar a Pedro de Vega para } \\
\text { llevar al Real, y el proceso, para que lo lleve el comendador a Ciudad Real. Que el regidor } \\
\text { Gonzalo de Monzón pida la llave a Doña Constanza, mujer de Diego de Vargas. }\end{array}$ \\
\hline 19 octubre 1500 & $\begin{array}{l}\text { El comendador Juan Amoroso entregó las escrituras del Real con sus sellos "y linpias e } \\
\text { enteras con sus caxas"; el corregidor y los regidores mandaron ponerlo en el arca. }\end{array}$ \\
\hline
\end{tabular}

48 Obviamente, las citas de la documentación en uso de los libros de actas son pocas, pero son representativas de los tipos documentales archivados, según confirma el libro de inventarios del archivo, en AVM, Libros Manuscritos, 19.

${ }^{49}$ Carmen LOSA CONTRERAS: El Concejo de Madrid en el tránsito de la Edad Media a la Edad Moderna, Madrid, Dykinson, 1999, pp. 124-125, 129 y 131-132. 


\begin{tabular}{|l|l|}
\hline 19 enero 1502 & Que se metan ese mismo día los privilegios en el arca. \\
\hline 15 mayo 1503 & $\begin{array}{l}\text { Que se caten las escrituras de casa del comendador Amoroso, de lo de El Real de Manzanares. } \\
\text { Que se metan los privilegios en el arca al día siguiente. }\end{array}$ \\
\hline 7 mayo 1512 & $\begin{array}{l}\text { Que Sazedo tome de casa del corregidor el arca de escrituras que ha de signar Cáceres; que } \\
\text { élesté presente a verlas sacar y signar. } \\
\text { Que le ayude Román y se le pague por ello. }\end{array}$ \\
\hline 21 abril 1514 & $\begin{array}{l}\text { Mandan librar tres reales y medio por una cerradura, una llave y unas chapas para las } \\
\text { esquinas del arca de los privilegios que está en Santo Domingo. }\end{array}$ \\
\hline 3 julio 1514 & $\begin{array}{l}\text { Que en el coro de la Iglesia de San Salvador hagan una bóveda de ladrillo donde esté el arca } \\
\text { de los privilegios que está en la Iglesia de Santo Domingo, con puertas y rejas de hierro } \\
\text { recio. Que quienes hicieran el memorial vean dónde se ha de colocar el arca en la Iglesia. }\end{array}$ \\
\hline 27 agosto 1515 & $\begin{array}{l}\text { Que todo lo que está por memorial fuera del arca (privilegios, etc.), se traslade y se meta } \\
\text { en el arca. }\end{array}$ \\
\hline $\begin{array}{l}\text { Se pidió un traslado de una sentencia (sobre la Melgraleja y el pleito de Pinto) que está en } \\
\text { el arca de los privilegios, el cual ya está en el Monasterio de Santo Domingo. Se conviene } \\
\text { que el arca se abra y se saque. } \\
\text { Se solicita un traslado a favor de la villa, para usar en el pleito con Pinto. Que los tres } \\
\text { llaveros vayan a sacar un traslado. }\end{array}$ \\
\hline
\end{tabular}

Fuente: elaboración propia a partir de los Libros de acuerdos del concejo..., vols. I al V.

Cabe la última observación, pero acaso la más importante. Un cuadro de estas características sería imposible de realizar en tan poco espacio si se quisieran recoger las citas en los mismo libros de acuerdos sobre documentación que no se archivaba, pues las referencias son enormemente cuantiosas.

En efecto, era normal que en cada reunión consistorial se citase, por cualquier razón, la existencia de un documento ${ }^{50}$. Eso sin contar con casos donde en una sola sesión el concejo podía otorgar numerosas escrituras. Póngase por caso la ajetreada mañana del 26 de julio de 1500, cuando el cabildo otorgó un poder al regidor Francisco de Vargas para presentar un testimonio de apelación en el Consejo Real de la sentencia de un licenciado y juez pesquisidor; también otorgó una petición sobre ello, una carta para Francisco de Vargas encargándole el caso, otra carta para el licenciado Angulo y otra carta al Bachiller de Prado, ambas sobre el mismo asunto ${ }^{51}$. Esto es un mero ejemplo, pues, los casos sobre el trajín documental existentes en los libros de actas son incontables.

\section{SOBRE EL DESEQUILIBRO DE INFORMACIÓN: TRAS EL RASTRO DEL USO DE LAS ESCRITURAS}

Se ha citado la escasa cantidad de información que ofrecen los libros de actas sobre el archivo y sus fondos. También se ha mencionado la gran cantidad de información que ofrecen sobre la documentación en general (no archivada, en curso y dispersa).

${ }^{50}$ Valga por caso el día 30 de abril de 1484, cuando ante el escribano y los testigos pertinentes Juan de Torres otorgó una carta de pago al concejo por valor de 18.000 maravedís, Libros de acuerdos del concejo..., t. I, p. 323.

${ }^{51}$ Libros de acuerdos del concejo..., t. IV, p. 213, 26 de julio de 1500. 
Esa desigualdad de información invita a observar las fuentes y a interrogarlas, planteándolas porqué brindan tantos datos sobre el tema documental y por qué tan pocos sobre el archivístico ${ }^{52}$.

Los libros de acuerdos acostumbraban a mencionar que se creaban y que circulaban documentos por el concejo, pero raramente aludían a dónde se guardaban. Incluso, en numerosas ocasiones, parece que las escrituras surgían por generación espontánea en el consistorio, en el sentido de que el cabildo las citaba pero no mencionaba de dónde procedían ni a dónde las llevaba después para conservarlas de forma regular. Por ejemplo, era muy común que el cabildo mandase hacer copias en el libro horadado del concejo ${ }^{53}$, pero no decía dónde se custodiaba dicho volumen. Esa misma parquedad afecta al destino y procedencia de numerosa documentación. ¿Cuál es la razón del citado desequilibrio de información? Seguir el rastro de las escrituras, viendo qué sucedía con ellas, dará alguna respuesta ${ }^{54}$. Obsérvese, por ejemplo, la presentación en el ayuntamiento de títulos de oficio. Cuando una persona conseguía un oficio proveído por el monarca debía presentar el título en el ayuntamiento en un plazo determinado. Así hizo García de la Cuadra el 17 de enero de 1486, cuando presentó una carta de corregidor firmada por el monarca. La carta se copió en el libro horadado. Tras presentarla, se leyó en el concejo en voz alta y se requirió al ayuntamiento que la obedeciese. El pesquisidor, allí presente, tomó la carta -en nombre de todo el concejo- y la puso encima de su cabeza y la obedeció, como carta del rey ${ }^{55}$.

Esa actitud reverente hacia una carta regia era común en la época, al igual que lo iba a ser posteriormente ${ }^{56}$. Y en el concejo era habitual. Como hizo Cristóbal de Vitoria cuando presentó una carta real que le proveía una escribanía de los reinos, y procedió de un modo similar: pidió que se cumpliera la carta, y en efecto, fue obedecida "con la reverencia devida", el cabildo le recibió en el oficio y él lo juró según marcaba el protocolo ${ }^{57}$. Lo mismo se hizo cuando fue presentada en el concejo una cédula real que mandaba que el ayuntamiento nombrase a un regidor, un letrado y unos peones para que acompañasen al licenciado que se ocupaba de los

${ }^{52}$ Es difícil (por no decir imposible) pensar en la mentalidad de la época existiera la lógica aplastante de que el material escrito se tenía que guardar directamente en el archivo y, por ser obviedad natural, no precisaba mención alguna. Pero esta posibilidad es poco probable, porque sólo el material escogido se archivaba, por tanto ya antaño se habría dispuesto la llamada de atención pertinente para mandar conservarlo, tal como se hacía en otros casos. Cabe buscar, entonces, otra explicación alternativa.

5328 de febrero de 1483, Libros de acuerdos del concejo..., t. I, p. 224. También el 24 de enero de 1486, Libros de acuerdos del concejo..., t. II, p. 4.

${ }^{54}$ Hice una primera aproximación a esta metodología con las ordenanzas en "Historia, fuentes e historiografía..."

${ }_{55}$ Libros de acuerdos del concejo..., t. II, p. 3.

${ }^{56}$ Como en AVM, Libros de Acuerdos, 26 de marzo de 1557. Una actitud similar también se estilaba en ámbitos privados, con libros a los que se rendía respeto, según recoge la literatura cervantina posterior. Así lo describe Cervantes en el escrutinio de los libros de Quijote efectuado por el barbero y el cura. Éste, antes de quemar el Espejo de Caballerías de Mateo Boyardo, planteó que si lo hallaba en lengua italiana lo pondría sobre su cabeza, alabando así la versión original y criticando la mala traducción que tuvo al castellano. Leonor ZOZAYA MONTES, voz Hernando Alcocer: p. 242, Carlos Alvar (dir.): Gran Enciclopedia Cervantina, Madrid, Castalia, 2005, vol. I, p. 242;

5720 de noviembre de 1486, Libros de acuerdos del concejo..., t. II, p. 36. 
términos de la villa. La escritura "fue obedecida con la reverencia devida, commo cédula de sus alteças" ${ }^{58}$, en señal de acatamiento.

En otros casos que concernían más a la villa y tierra de Madrid, el documento se leía, se aceptaba y se reverenciaba para que se cumpliera o, según procediese, se notificaba a quienes correspondiera o se difundía mediante una tabla o con pregón en lugares concurridos, con la intención de que nadie pretendiera ignorancia ${ }^{59}$. Sirve de ejemplo cuando los capitulares, ayuntados en el concejo, leyeron una sentencia sobre la elección de los oficios, más todo lo contenido en aquel escrito. Ante tal juramento todos dijeron amén, "lo qual se hizo públicamente en la dicha yglesia"60.

Era común que se hiciera pública la información. El concejo necesitaba informar a la villa con frecuencia, para lo que intentaba que la voz llegara de unos a otros. Así sucedió por ejemplo el 20 de junio de 1496, cuando notificó una "ley e ordenança [...] para que ninguna persona sea osado de tomar moço de serviçio, así para la soldada como para azemilero [...] e mandáronlo pregonar e notificar a los seismeros para que lo hagan saber en sus seismos" ${ }^{1}$. La notificación era el acto de comunicar, generalmente por escrito, una decisión adoptada por el concejo en una sesión capitular, que por lo común obligaba a algo a quien se comunicaba ${ }^{62}$.

Si los documentos en cuestión eran unas ordenanzas, era normal que se presentasen en el ayuntamiento, se aprobaran, copiasen, publicasen y pregonasen o se escribiesen en una tabla ${ }^{63}$. Los ejemplos al respecto son numerosos, y hacen imaginar una rica cultura oral, pendiente de la divulgación de la información en la época.

Así se aprecia, por un lado, que el concejo anotaba en los libros de acuerdos que existían infinidad de documentos y que la institución pedía que se divulgasen los contenidos, pero, por otro lado, apenas citaba nada sobre su conservación. Ello invita a sospechar que al cabildo le importaba fundamentalmente la difusión de la información, para que se cumpliera el mensaje. Esa finalidad primaba sobre el interés de conservar su soporte documental, por ello ni reparaba en citarlo en las fuentes administrativas.

Además, las fuentes registran más comportamientos ante las escrituras, como los que dudaban de ellas respaldándose en la costumbre. Así las ignoraban, no las aceptaban ni las difundían para impedir que se cumplieran, haciendo caso omiso de su dictado. Ese tipo de incumplimientos tenía lugar si no convenía a la villa, porque

5820 de febrero de 1486, Libros de acuerdos del concejo..., t. II, p. 8.

59 Los casos son innúmeros en los cinco volúmenes de Libros de acuerdos del concejo... Es normal ver al margen de muchos acuerdos la confirmación del escribano y los testigos de que se ha pregonado ante determinados testigos. Valga por caso el del 20/10/1497, Libros de acuerdos del concejo..., t. III, p. 335. Hay menos ejemplos de tablas, pero también hay.

60 Constan muchos más ejemplos al respecto, también sobre testigos, el mismo día, en 29 de septiembre de 1478, Libros de acuerdos del concejo..., t. I, p. 33-37.

${ }^{61}$ Libros de acuerdos del concejo..., t. III, p. 240.

${ }_{62}$ En general, el escribano se encargaba de que llegase tal conocimiento. Fernando PINO REBOLLEDO: Tipología de los documentos municipales, siglos XII-XVII, Valladolid, Asociación para la Defensa y Conservación de los Archivos, 1991 ..., p. 304; en general, véase pp. 304-309.

${ }^{63}$ Libros de acuerdos del concejo..., t. III. p. 88; 27/6/1494, Libros de acuerdos del concejo..., t. III, p. 117; 16/1/1494; Libros de acuerdos del concejo..., t. IV, p. 31; 25/5/1498. 
contravenía sus intereses económicos o políticos, aunque se hacía en nombre de la costumbre. Ésta se apelaba con frecuencia ante cualquier desavenencia política ${ }^{64}$.

En efecto, se daban casos en que el cabildo aludía a la costumbre según le convenía, siguiendo en parte un criterio aleatorio, contrariando lo que dictaba un escrito si era necesario. Véase el caso de cuando Rabí Abraán del Sobrado fue al concejo el 30 de marzo de 1484. Acudió allí en nombre de quien le había dado un poder, su hermano el recaudador Rabí Yudá ${ }^{65}$. Presentó, por un lado, una carta de recudimiento, en la que los reyes le proveían de la recaudación de las tercias y alcabalas de la villa y tierra de Madrid. El cabildo, al aceptar la carta, la reverenció y afirmó obedecerla, aceptándole en el oficio de arrendador y recaudador. Después, mandó pregonarla públicamente por las plazas y mercados de la villa ${ }^{66}$.

Sin embargo, por otro lado, presentó el mismo día otra carta ante la que el concejo adoptó una actitud escéptica. Era una "carta de seguro", librada por los contadores mayores, por la cual los reyes amparaban y defendían a Rabí y a su apoderado, y además, mandaban que se les hospedara gratuitamente ${ }^{67}$. Los capitulares dijeron "que la obedecían con la rreuerençia que debían". No obstante, en cuanto a su cumplimiento, mandaron guardar y cumplir sólo lo relativo al seguro, y pregonarlo públicamente. Se negaron a darle "posadas sin dineros", según dijeron, y no mandaron cumplir esa parte ni pregonarla, "porque aquello es cosa nueva y cosa que nunca se acostunbró en esta dicha villa". A ello, bien es cierto, sumaron "los agravios que costaba", y que además esa decisión regia había sido ganada "con rrelación no verdadera [...]"68.

\section{CONCLUSIONES}

Varias fuentes primarias informan sobre la documentación municipal y sobre los archivos del concejo madrileño. De todas ellas, los libros de acuerdos aportan más riqueza informativa sobre qué sucedía con los archivos del cabildo en la época y, principalmente, sobre cómo y dónde se usaba la documentación municipal, tanto la archivada como la no archivada. Aun dentro de esa riqueza, al estudiarlos y comparar la cantidad de información que registran sobre unos y otros temas, sorprende comprobar que ofrecen escasos datos sobre los archivos y sus fondos, pero brindan numerosos datos sobre qué se hacía con las escrituras municipales en curso. Esa información permite observar un contexto donde la mayoría de los documentos, lejos de ser archivados, circulaban cotidianamente por el ayuntamiento o en manos de oficiales de la villa.

${ }^{64}$ Como por ejemplo alegaron los villanos de Madrid en el juicio de residencia de Rodrigo de Mercado, 7 de mayo de 1484, Libros de acuerdos del concejo..., t. I, p. 325-326.

${ }^{65}$ Constaba como recaudador el año anterior, en el Libro Horadado, donde también se copió la carta que entonces llevaba.

${ }^{66}$ Libros de acuerdos del concejo..., t. I, p. 306.

67 “Así mismo presentó el dicho Rabí Abraán presentó una carta de seguro de los dichos Reyes [...] por la qual pareçe que sus altezas toman so su seguro e anparo e defendimiento rreal al dicho Rabí Hudá o al quel dicho su poder uviere, e mandan que les sean dadas posadas sin dineros". Libros de acuerdos del concejo..., t. I, p. 306.

${ }_{68}$ Libros de acuerdos del concejo..., t. I, p. 306. 
El citado desequilibrio de información en las fuentes invita a reflexionar sobre qué le interesaba al ayuntamiento hacer con un documento que se archivaba y qué hacía con uno que no se archivaba en la época. Para atender a la primera cuestión he observado qué documentos se archivaban. Eran escasos y consistían principalmente sentencias y privilegios sobre pleitos, como el de El Real de Manzanares o el de Pinto. Éstos servían en litigios. Es decir, la villa archivaba documentos para usar entre partes (la villa y otro lugar), que competían a asuntos puntuales, que no era menester que se enterase toda la villa y tierra de su contenido.

Para atender a la segunda cuestión, qué le interesaba hacer al ayuntamiento con un documento que no se archivaba, he seguido el rastro de ese material escrito. Me he centrado en esa mayoría de ocasiones cuando el ayuntamiento pretendía que la villa cumpliese algo que dictaba un escrito que atañía al concejo o a la sociedad en general. Con ese fin era necesario seguir cierto protocolo requerido, haciéndole las reverencias pertinentes en señal de acatamiento (como colocarlo sobre la cabeza), que el concejo lo aceptase y que se difundiera mediante los cauces pertinentes (lectura en el consistorio, notificación al afectado, publicación mediante pregón en lugares concurridos con altas voces o escritura sobre una tabla). Así, en caso de que el cabildo quisiera ignorar el contenido de un documento, podía hacerlo sin reverenciarlo ni acatarlo ni difundirlo, como si no tuviera valor.

Frente al interés generalizado por la difusión de la información, se aprecia un interés muy limitado hacia la conservación documental, restringido a documentación relativa a privilegios y sentencias. Esas inclinaciones eran comprensibles, habida cuenta de la escasa experiencia archivística en la villa, que en parte se justificaba por la juventud de los archivos municipales y por la importancia de la cultura oral sobre la escrita en la época. 